\title{
Development of a Perforated Panel for Acoustic Conditioning Based on Colombian Guadua Fiber (Guadua Angustifolia Kunth)
}

\section{Desarrollo de un Panel Perforado para Acondicionamiento Acústico Basado en Fibra de Guadua Colombiana (Guadua Angustifolia Kunth)}

\author{
Darío Alfonso Páez Soto ${ }^{1}$, Luis Jorge Herrera Fernández¹, Oscar Esneider Acosta Agudelo ${ }^{1}$, \\ Shymmy Wilbermer García Bustos ${ }^{1}$, Marcelo Herrera Martínez ${ }^{2 *}$ \\ ${ }^{1}$ GRIAP-Grupo de Investigación en Acústica Aplicada, Ingeniería de Sonido, Universidad de San Buenaventura, Bogotá, Colombia. \\ ${ }^{2}$ School of Engineering and Natural Sciences, Faculty of Mechanical and Informatics Engineering, University of Iceland
}

\begin{abstract}
The present research is about the practical implementation of a perforated panel for acoustic conditioning, manufactured with guadua, a typical Colombian fiber. The developed panel is checked for its acoustic conditioning properties. Guadua is an attractive natural resource with great potential for renovation and use in sustainable construction. Here, its acoustic absorption coefficient is measured and validated; finally, a physical panel is built for acoustic conditioning purposes.
\end{abstract}

Keywords: Perforated panels, Acoustic Absorption, Sustainable Development, Acoustic Conditioning.

\section{Resumen}

La presente investigación trata acerca de la implementación práctica de un panel perforado para acondicionamiento acústico fabricado con guadua, una fibra natural típica colombiana. El panel desarrollado es verificado a través de su propiedad de acondicionamiento acústico. La guadua es un recurso atractivo y con gran potencial de renovación para su uso en la construcción sostenible. Aquí, su coeficiente de absorción acústica es medido y validado; finalmente, un panel físico es construido para propósitos de acondicionamiento acústico.

Palabras clave: Paneles perforados, Absorción acústica, Desarrollo Sostenible, Acondicionamiento Acústico.

\section{Introduction}

In 1992, in Rio de Janeiro (Brazil), the United Nations came to define the basic principles of what is known as Sustainable and Sustainable Development (United Nations 1987). Implementation of these principles seeks to maintain a balance of the global ecosystem, in terms of ecological preservation, use of resources, as well as, the reduction of hunger, disease and poverty. In acoustics, this agenda, known as Agenda 21 [1], specifically defines:

- The reduction of noise levels: noise levels that induce hearing impairment are unacceptable.

*Corresponding Author.

E-mail: mh2musicamarcelo@gmail.com
- Noise that decrease in quality of life, causing sleep disturbances, word interference and / or severe nonconformity is unacceptable.

- Noise that interferes with spoken communication, learning and teaching is unacceptable.

In addition to the problem of noise, the Brundtland Commission [2] also defines as a basic precept that sustainable development also includes development with minimum energy and material consumption, also, mainly low-weight constructions made of recyclable material obtained from machinery, vehicles and others.

How to cite: Páez, D.A., Herrera, L. J., Acosta, O. E., García, S. W. Herrera, M., Development of a Perforated Panel for Acoustic Conditioning Based on Colombian Guadua Fiber (Guadua Angustifolia Kunth), TECCIENCIA, Vol. 13 No. 25, 11-18, 2018 DOI: $\mathrm{http}: / / \mathrm{dx}$.doi.org/10.18180/tecciencia.2018.25.2 


\section{TECCIENCIA}

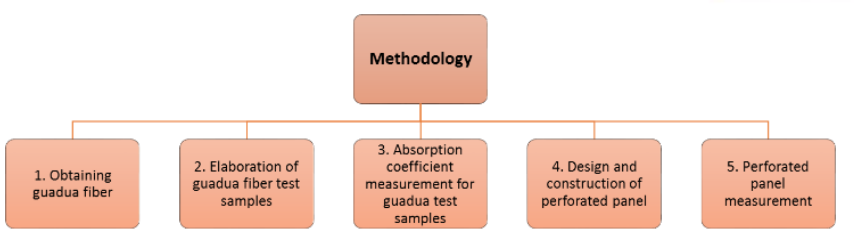

Figure 1 Methodology applied for the design and measurement of the perforated acoustic panel.

In that sense, this research seeks to contribute to the development of Colombian industry, through the creation of specialized acoustic systems, capable of competing in the market for quality and innovation.

Mechano-acoustic systems have been described in the past by several authors [3] [4] [5] [6]. Electroacoustic transducers, partitions, acoustic barriers, mufflers, and acoustic conditioning systems, such as the acoustic panel that is developed in this research, are examples of applications of these systems.

Acoustic conditioning systems have been fully described by Trevor Cox and Peter D'Antonio [7]. Among these systems we find absorbers and acoustic diffusers, designed conditioning of study rooms, conference rooms, theaters, acoustics chambers and, in general, sites that require acoustic treatment. This acoustic treatment is carried out to adjust reverberation time, early room reflections, and others acoustic parameters to homogenize sound field.

Likewise, acoustic insulation systems have been widely described by Randall F. Barron [8] as examples of them we have partitions, barriers and silencers. These systems mitigate the sound transmission in adjacent rooms, structural noise, airborne sound transmission, and minimize the sound pressure levels between the exterior and interior of a building.

Both types of systems, conditioning and insulation, are applied in construction. Therefore, developing and applying this natural fiber to improve acoustic performance of these acoustics systems energizes the economy of a society, and impact the environment in a significant way. All the above, based on based on the principles of sustainable construction [9] [10] as well as acoustic applications of this systems [11] [12] [13].

\section{Methodology for the design of the acoustic- mechanical system}

The methodology implemented for the design and measurement of the perforated acoustic panel filled with guadua fiber is shown in Figure 1.

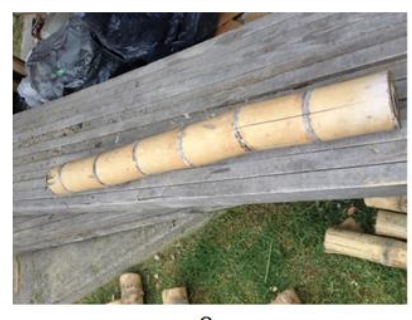

a.

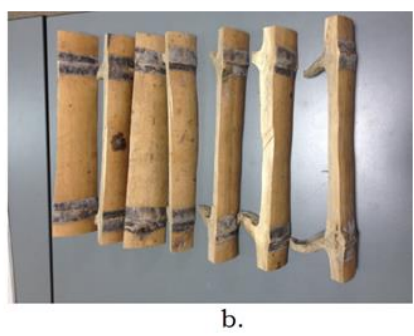

b.
Figure 2 (a) Guadua residues obtained for the test. (b) Guadua divided in internodes.

At first, it is necessary to obtain guadua fiber from the plant trunk which was used to fill the perforated panel; this process was done in manual way. Secondly, with the fiber obtained samples to be used in the measurement system were elaborated. Afterwards, absorption coefficient for central band frequencies between $125 \mathrm{~Hz}$ and $3150 \mathrm{~Hz}$ was measured. Subsequently, once the fiber was characterized, design and construction of the perforated panel for a specific frequency was done. Finally, the acoustic performance of the panel developed was tested in a room with high reverberation time.

\subsection{Guadua fiber obtention}

The guadua trunk used for obtaining the guadua fiber was taken from waste material implemented for other applications by the Guadua and Wood Research Group of the National University of Colombia, as shown in Figure 2a.

The guadua trunk was divided into internodes, as can be seen in Figure 2b, which were marked to identify each one of the specimens. Then, following steps presented in Figure 3, guadua fiber was obtained.

To begin, physical characterization of test pieces to obtain dimensions and weights was done. Then, it was necessary to determine a mixture content and fiber density for which the Colombian Technical Standard NTC 5525 [14] was used. Afterwards, fibers separation by a chemical process, inserting the specimens in a $10 \%$ sodium hydroxide solution for 72 hours was done, this step was complemented with manual brushing of the specimens with a fine metallic grating. Then, weight fiber as a function of the initial specimen was obtained. Finally, fiber samples for the measurement of absorption coefficient were armed.

\subsection{Humidity content percentage}

From the initial sample of guadua, seven specimens were obtained by initiating the process of determining the content of the mixture. Initial, green and anhydrous weight stablished for each specimen is presented in Table 1. 


\section{TECCIENCLA}

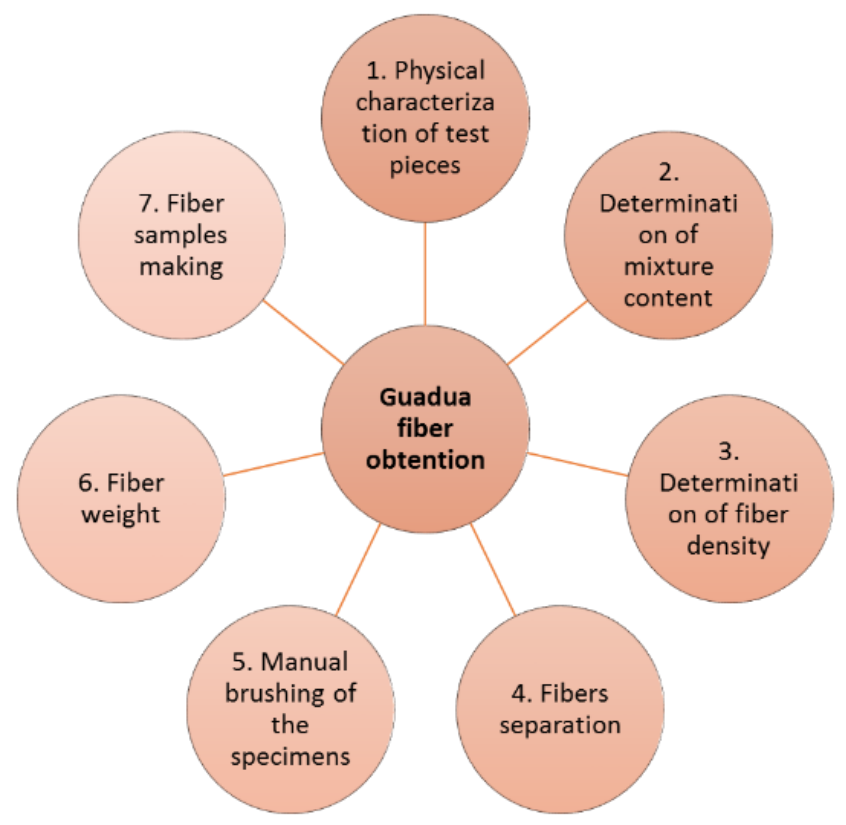

Figure 3 Steps followed to obtain guadua fiber.

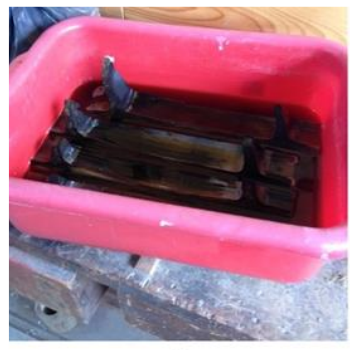

a.

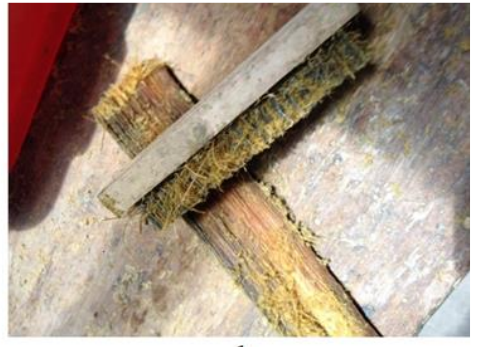

b.
Figure 4 (a) Samples submerged in sodium hydroxide. (b) Sample brushing process.

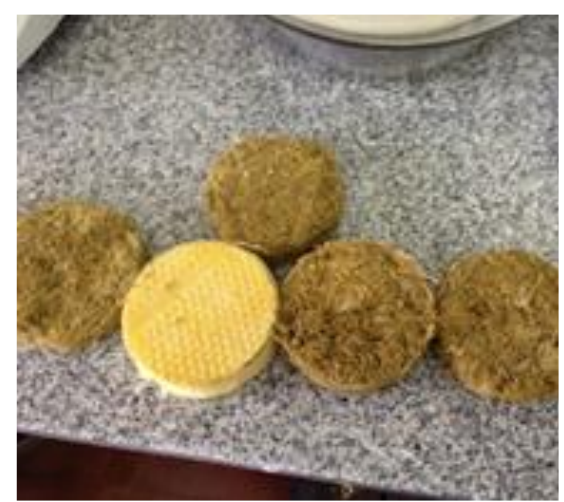

Figure 5 Finished fiberglass and guadua fiber samples.
Table 1 Physical properties of the samples.

\begin{tabular}{|c|c|c|c|c|}
\hline Sample & $\begin{array}{c}\text { Initial } \\
\text { weight (gr) }\end{array}$ & $\begin{array}{c}\text { Weight in } \\
\text { green (gr) }\end{array}$ & $\begin{array}{c}\text { Weight } \\
\text { without } \\
\text { water } \\
\text { content (gr) }\end{array}$ & $\begin{array}{c}\% \text { of } \\
\text { humidity } \\
\text { content }\end{array}$ \\
\hline 1 & 150.38 & 220.12 & 134.63 & 11.70 \\
\hline 2 & 124.80 & 190.14 & 111.38 & 12.00 \\
\hline 3 & 156.07 & 229.89 & 140.01 & 11.50 \\
\hline 4 & 141.90 & 196.89 & 128.05 & 10.80 \\
\hline 5 & 132.50 & 192.45 & 118.30 & 12.00 \\
\hline 6 & 167.58 & 239.48 & 150.97 & 11.00 \\
\hline 7 & 115.20 & 163.30 & 102.90 & 12.00 \\
\hline
\end{tabular}

In order to obtain mixture content $(\mathrm{CH})$, Equation 1 was applied.

$$
C H=\left(\frac{m-m o}{m o}\right) 100,
$$

Where, $m$ represents specimen mass before the drying process and $m o$ is specimen mass after drying process.

\subsection{Sample density}

According to standard NTC 5525 [14], to obtain the density of the samples, it is required to determine the mass in anhydrous state and the volume in green state. These values do not vary with respect to the climatic conditions. The values of anhydrous mass, volume in green state and density of each sample can be observed in Table 2. It is important to highlight, that samples average density is $0.45 \mathrm{~kg} / \mathrm{m} 3$.

\subsection{Elaboration of guadua fiber test samples}

Separation and extraction of fiber was done by means of a mechanical-chemical method using sodium hydroxide. This element is an alkaline that manages to break bonds between lignin molecules in a $10 \%$ solution. By keeping the samples for approximately 120 hours, after which they are washed with water, the brushing of the samples was done with a metallic brush with thin ropes to obtain a very fine fiber. In Figure $4 \mathrm{a}$, can be seen the samples in sodium hydroxide solution.

Each sample was brushed, and the fiber extracted considering that the outer bark of the guadua is harder, reason why it is impossible to remove it in its entirety, in Figure $4 \mathrm{~b}$ fiber brushing process is observed. Once the process of brushing and manual extraction of the fibers was finished, the amount of fiber obtained from each sample was weighed wet and dry to proceed to assemble the test pieces to measure the absorption coefficient. The amount of fiber obtained per sample is referenced in Table 3. 
Table 2 Weight values, volume and density of samples.

\begin{tabular}{|c|c|c|c|}
\hline Sample & $\begin{array}{c}\text { Weight without } \\
\text { water content } \\
(\mathrm{gr})\end{array}$ & $\begin{array}{c}\text { Volume in } \\
\text { green }(\mathrm{mm} 3)\end{array}$ & $\begin{array}{c}\text { Density } \\
(\mathrm{Kg} / \mathrm{m} 3)\end{array}$ \\
\hline 1 & 134.63 & 310 & 0.43 \\
\hline 2 & 111.38 & 282 & 0.39 \\
\hline 3 & 140.01 & 310 & 0.45 \\
\hline 4 & 128.05 & 254 & 0.50 \\
\hline 5 & 118.30 & 260 & 0.46 \\
\hline 6 & 150.97 & 326 & 0.46 \\
\hline 7 & 102.90 & 227 & 0.45 \\
\hline
\end{tabular}

Total fiber obtained was 247.1 grams, and with this amount of fiber test pieces were processed. Because of the tube used for the measurement has an internal diameter of 4-inches, samples kept the same dimeter but with 1-inch thickness and 20.5 grams weight. Finally, in order to do a comparison between guadua fiber and a typical absorption material, a sample of glass fiber was made.

To do a comparison among different guadua fiber compositions 12 test samples, based on NTC 5525 [14], with a weight of 20.6 grams were built. Likewise, to maintain the shape and dimensions of the comparison specimen and sample holder, the fiber of each of the specimens was compressed with a standard weight of 258308 grams in a circular mold with an internal dimension of 4 inch, and each sample was kept under this weight for approximately 5 days. Some specimens can be seen in Figure 5.

\section{Results and discussion}

In this section, the physical characterization, panel elaboration and acoustic measurements applying international standards are described.

\subsection{Absorption coefficient measurement}

Measurement process was carried out under the process standardized by ISO 10534-2 [15], measurement system characteristics and measurement process are described below. Tube dimensions, sample location and microphones positions can be seen in Figure 6.

Working frequency limit values for analysis were obtained according with ISO 10534-2. In that sense, distances needed for the measurements were defined through the following calculations.
Table 3 Initial weight and fiber weight of the samples.

\begin{tabular}{|c|c|c|}
\hline Sample & Initial weight (gr) & Fiber weight (gr) \\
\hline 1 & 150.38 & 37.60 \\
\hline 2 & 124.80 & 31.20 \\
\hline 3 & 156.07 & 39.02 \\
\hline 4 & 141.90 & 35.48 \\
\hline 5 & 132.50 & 33.13 \\
\hline 6 & 167.58 & 41.90 \\
\hline 7 & 115.20 & 28.80 \\
\hline
\end{tabular}

Highest tube working frequency $f_{u}$ corresponds to

$f_{u}<\frac{0.5 c_{o}}{d}$,

Here $\mathrm{d}$ is the internal diameter of the tube in meters $(d=0.1016 \mathrm{~m})$ and $\mathrm{c}_{\mathrm{o}}$ is sound speed propagation $(343 \mathrm{~m} / \mathrm{s})$. Thus, the higher frequency of work $f_{u}$ calculated using Equation 2 was $1687 \mathrm{~Hz}$. The distance between the microphones $s$ is calculated using:

$\mathrm{f}_{\mathrm{u}} \mathrm{s}<0.45 \mathrm{c}_{\mathrm{o}}$.

$\mathrm{s}<\frac{0.45 \mathrm{c}_{\mathrm{o}}}{\mathrm{f}_{\mathrm{u}}}$.

$\mathrm{s}<0,091 \mathrm{~m}$

On the other hand, lower frequency limit depends on the distance between the microphones and system accuracy, but as a rule, the distance between microphones should exceed by $5 \%$ the wavelength of the lowest frequency of interest, if the requirement of the distance between microphones is met. Lower tube frequency $f_{i}$ is obtained by means of Equation 6 ,

$$
f_{i}=\frac{C_{o} \cdot 0.05}{S} \text {. }
$$

\subsubsection{Calibration signals acquisition}

During signals acquisition (calibration and measurement), analysis software enables the capture of amplitude and phase values at each microphone position. Once these initial data were obtained, signal processing was done in MATLAB. Microphones were set in position 1 and 2 (arrangement can be seen in Figure 6). The signal corresponding to the transfer is acquired $H_{12}^{\prime}(w)$ in Figure 7. 


\section{TECCIENCIA}

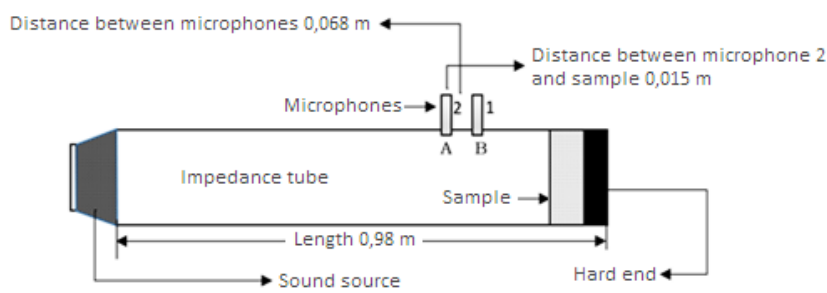

Figure 6 Initial weight and fiber weight of the samples. Considering the parameters established in ISO 10534-2 [15], an absorbent material was added to avoid possible turbulence generated by the sound source. Likewise, the sample to be measured is placed in the sample holder.

When the microphone position is changed, then transfer function is obtained, $H^{\prime \prime}{ }_{12}(w)$. Once the transfer functions in position 1 and 2 were obtained, the calibration function was obtained by mean of Equation 7 .

$$
H_{12}(w)=\sqrt{H_{12}^{\prime}(w) H^{\prime \prime}{ }_{12}(w)}=\left|H_{12}\right| e^{j \emptyset}
$$

\subsection{Sample measurement}

Once the calibration function is obtained, the guadua sample No. 1 is located and the system is configured in position No. 1 , to acquire the transfer function $H^{\prime}{ }_{12}(w)$, still without correction. Overall setup may be seen in Figure 8.

Sample 1 transfer function is shown in Figure 9. This same procedure was performed for each of the samples. The absolute value of the transfer function (once corrected) can be seen in Figure 10.

\subsection{Absorption coefficient obtention}

Once corrected sample signal is obtained, reflection coefficient and absorption coefficient were obtained. Table 4 shows absorption coefficients results found per octave band from $150 \mathrm{~Hz}$ to $3150 \mathrm{~Hz}$. The average absorption coefficient of the twelve samples is shown below in Figure 11.

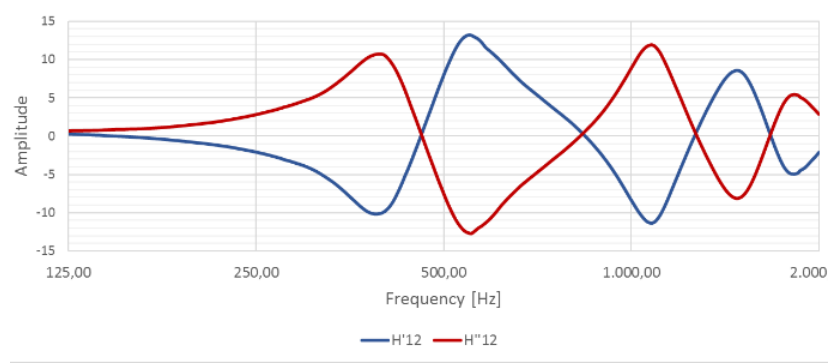

Figure 7 Transfer function $H^{\prime}{ }_{12}(w)$ and $H^{\prime \prime}{ }_{12}(w)$.

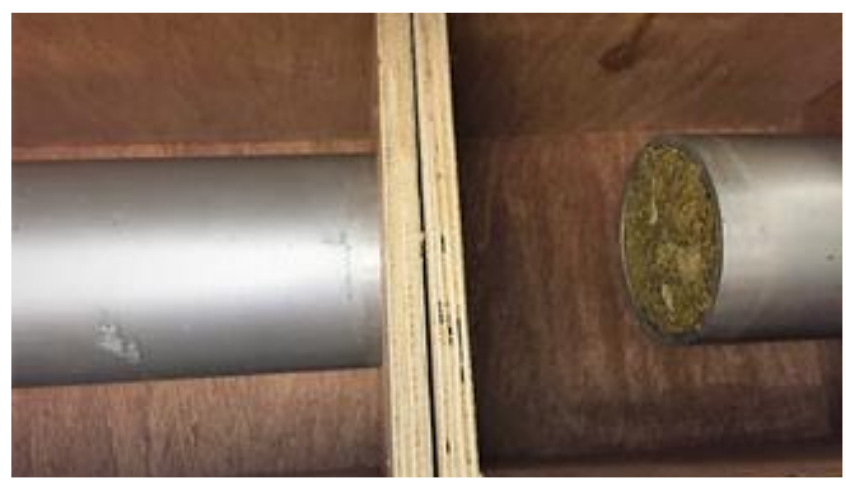

Figure 8 Sample assembly in the measurement tube.

\subsection{Design of the perforated panel based in guadua}

According to the proposed theory, a perforated panel tuned to $476 \mathrm{~Hz}$ is designed. This to perform acoustic energy attenuation in medium-low frequency where acoustic panels and guadua fiber abortion coefficient presents good acoustic performance.

Panel design required to estimate two parameters. The first one was end tube acoustic correction, $D^{\prime}=D+1,6 a$, where $D$ is panel thickness $(0,5 \mathrm{~cm})$ and $a$ is hole radius $(0,5 \mathrm{~cm})$. In this case $D^{\prime}=1.3 \mathrm{~cm}$. The second one was perforation percentage, $p=\pi a^{2} / D_{1} D_{2}$, where $D_{1}$ and $D_{2}$ are horizontal $(5 \mathrm{~cm})$ and vertical $(4 \mathrm{~cm})$ distance between holes, respectively. The percentage of drilling calculated was $p=$ 0.03927 . Finally, panel holes were evenly distributed over the surface and distance from the panel to the rigid wall was $4 \mathrm{~cm}$. In Figure 12 the distance between panel holes can be seen.

The guadua sheet used for the acoustic panel construction has a thickness $D$ equal to $0.5 \mathrm{~cm}$ and has a surface area of $1.2 \mathrm{~m}^{2}(1 \mathrm{~m} \mathrm{x} 1.2 \mathrm{~m}$.). The equation used to determine the panel frequency of resonance was:

$$
f_{o}=5840 \sqrt{\frac{p}{D^{\prime} d}} .
$$

As said before, resonance frequency obtained with panel thickness and holes separation was $476 \mathrm{~Hz}$. It can be analyzed that percentage of perforation is function of the distance between vertical and horizontal perforations, and the respective radius of each of them. If the distance between the vertical and horizontal perforations is increased, perforation percentage will be lower, and the resonance frequency will decrease, and if the distance to each perforation is not increased, but the radius of each of them, an increase in the resonance frequency of the panel will be produced. 


\section{TECCIENCLA}

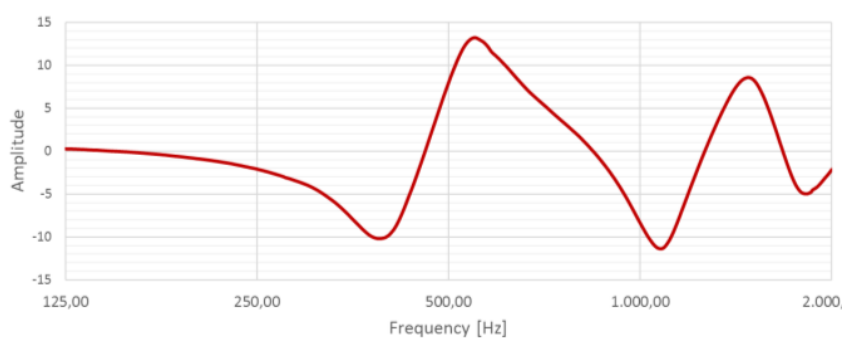

Figure 9 Transfer function of the sample No. 1 without correction.

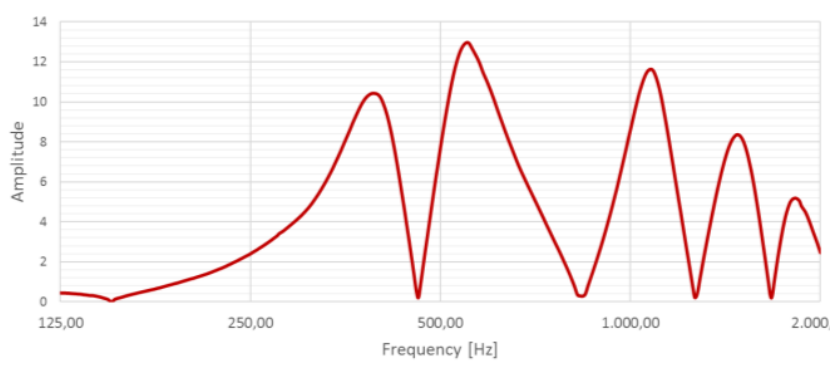

Figure 10 Corrected transfer function of sample 1.

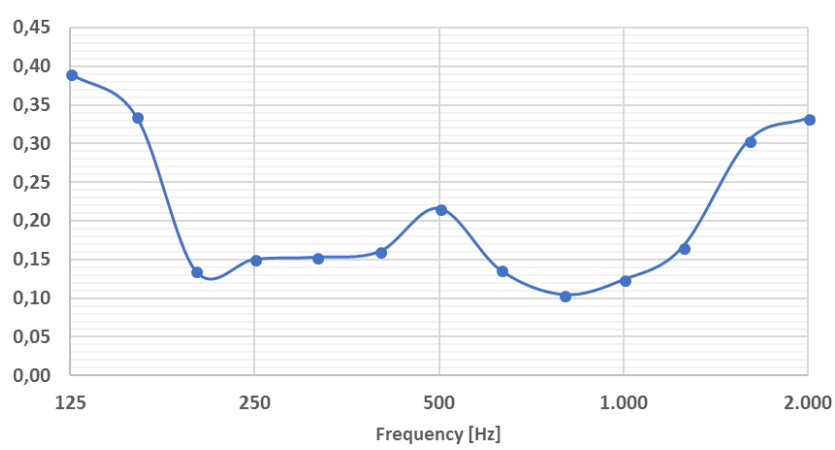

Figure 11 Average absorption coefficient of the 12 guadua fiber samples.

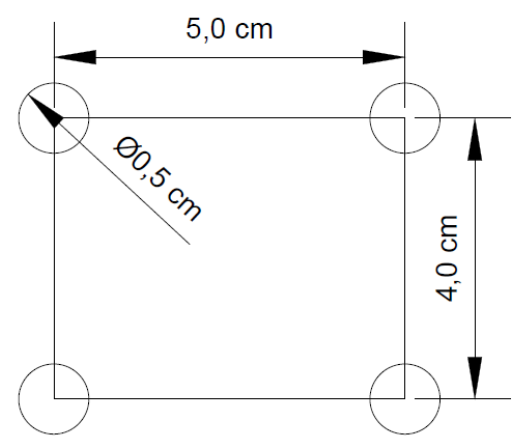

Figure 12 Distance between perforated panel holes.
Table 4a Absorption coefficient of 12 samples of guadua fiber from $125 \mathrm{~Hz}$ to $630 \mathrm{~Hz}$.

\begin{tabular}{|c|c|c|c|c|c|c|c|c|}
\hline Sample & 125 & 160 & 200 & 250 & 315 & 400 & 500 & 630 \\
\hline 1 & 0,38 & 0,28 & 0,10 & 0,14 & 0,16 & 0,17 & 0,20 & 0,15 \\
\hline 2 & 0,32 & 0,29 & 0,18 & 0,20 & 0,20 & 0,19 & 0,27 & 0,17 \\
\hline 3 & 0,40 & 0,29 & 0,08 & 0,12 & 0,13 & 0,14 & 0,17 & 0,14 \\
\hline 4 & 0,37 & 0,34 & 0,12 & 0,13 & 0,13 & 0,13 & 0,18 & 0,12 \\
\hline 5 & 0,40 & 0,34 & 0,09 & 0,12 & 0,13 & 0,15 & 10,17 & 0,13 \\
\hline 6 & 0,44 & 0,33 & 0,06 & 0,10 & 0,13 & 0,15 & 0,15 & 0,13 \\
\hline 7 & 0,43 & 0,33 & 0,14 & 0,15 & 0,15 & 0,15 & 0,19 & 0,12 \\
\hline 8 & 0,37 & 0,43 & 0,24 & 0,21 & 0,18 & 0,17 & 0,26 & 0,10 \\
\hline 9 & 0,45 & 0,39 & 0,14 & 0,15 & 0,16 & 0,19 & 0,20 & 0,14 \\
\hline 10 & 0,33 & 0,33 & 0,18 & 0,18 & 0,17 & 0,16 & 0,23 & 0,14 \\
\hline 11 & 0,41 & 0,36 & 0,18 & 0,18 & 0,17 & 0,18 & 0,35 & 0,17 \\
\hline 12 & 0,39 & 0,32 & 0,12 & 0,13 & 0,13 & 0,15 & 0,23 & 0,13 \\
\hline
\end{tabular}

Table 4b Absorption coefficient of 12 samples of guadua fiber from $800 \mathrm{~Hz}$ to $3150 \mathrm{~Hz}$.

\begin{tabular}{|c|c|c|c|c|c|}
\hline Sample & 800 & 1000 & 1250 & 1600 & 2000 \\
\hline 1 & 0,13 & 0,10 & 0,08 & 0,34 & 0,43 \\
\hline 2 & 0,14 & 0,13 & 0,12 & 0,56 & 0,52 \\
\hline 3 & 0,11 & 0,10 & 0,08 & 0,07 & 0,29 \\
\hline 4 & 0,08 & 0,09 & 0,07 & 0,28 & 0,37 \\
\hline 5 & 0,08 & 0,09 & 0,08 & 0,71 & 0,32 \\
\hline 6 & 0,09 & 0,08 & 0,07 & 0,22 & 0,30 \\
\hline 7 & 0,08 & 0,08 & 0,06 & 0,44 & 0,38 \\
\hline 8 & 0,08 & 0,09 & 0,06 & 0,14 & 0,38 \\
\hline 9 & 0,09 & 0,10 & 0,09 & 0,44 & 0,31 \\
\hline 10 & 0,11 & 0,10 & 0,08 & 0,30 & 0,34 \\
\hline 11 & 0,17 & 0,34 & 0,85 & 0,06 & 0,19 \\
\hline 12 & 0,10 & 0,19 & 0,36 & 0,09 & 0,17 \\
\hline
\end{tabular}

It is also important to highlight that the distance $D$ ' of the panel to the back rigid wall influences the resonance frequency. Thus, as $D^{\prime}$ increases attenuation will be located at lower frequencies, and by reducing this distance the volume of air between the panel and the rigid wall decrease, and attenuation will take place in higher frequencies. In Figure 13, dimensions and constructed guadua panel are shown. 


\section{TECCIENCIA}

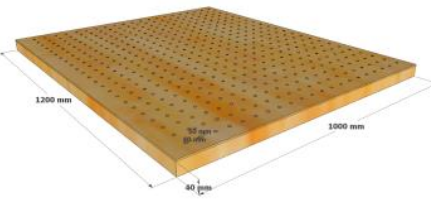

a.

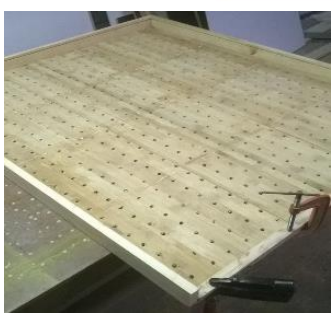

b.
Figure 13 (a) Preliminary design of the perforated panel. (b) Constructed guadua panel.

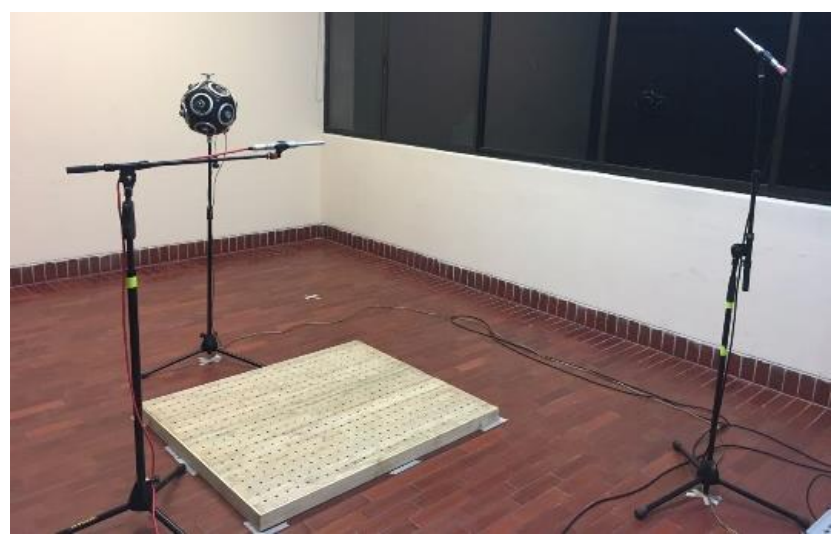

Figure 14 Position of the perforated panel inside the room.

\subsection{Experimental measurement of the panel}

Measurement was done in accordance with ISO Standard 3382-2. First, reverberation time of a room at University of San Buenaventura (Bogotá-Colombia) with reflective materials was performed. Then, the panel was introduced into the room and the reverberation time was measured again. Thus, with the obtained values it was possible to make a comparison for both situations. In Figure 14 can be seen the room and panel position inside it.

Based on measurement results showed in Figure 15 can be concluded that, reverberation time values obtained with the panel show that the manufacture of a perforated panel with material made of guadua fiber is suitable for acoustic conditioning purposes (acoustic absorption in an enclosure). Specifically, this behavior can be observed when comparing the curves in Figure 15 where in all band frequency a significant reduction in reverberation time with the perforated panel can be observed. It should be emphasized that, if there is a greater surface area of the panel inside the room, in several sides of the parallelepiped that forms it, reverberation time values will have a more significant decrease, due to a greater absorption of the acousticmechanical element.

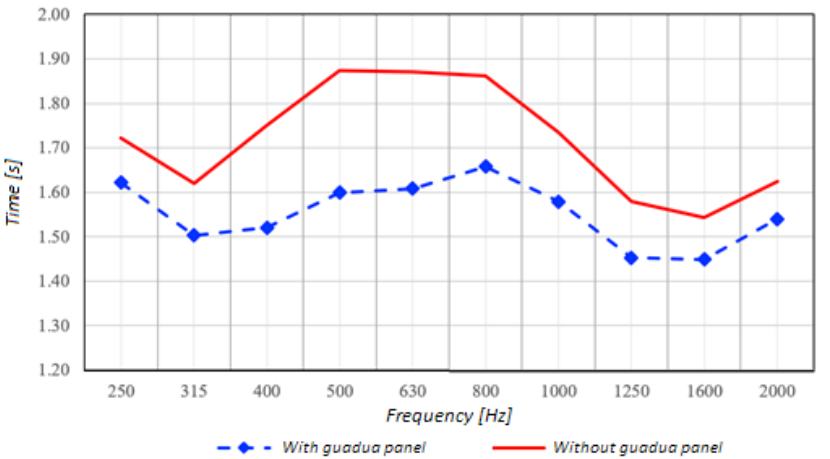

Figure 15 Reverberation Time measurement: Empty room and with perforated panel inside the room.

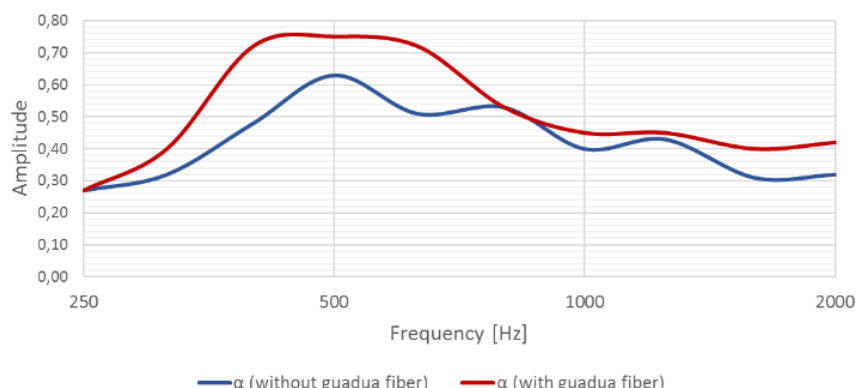

Figure 16 Panel absorption coefficient with and without guadua fiber.

It is important to highlight that for a desired acoustic solution or application, it is recommended to make a preliminary reverberation time prediction with room surfaces and materials, and then, to estimate appropriated acoustic absorption value considering panel surface.

Finally, panel acoustic absorption coefficient with and without guadua fiber is showed in Figure 16. In this case, maximum acoustic absorption is occurring at $500 \mathrm{~Hz}$ center band frequency, where panel resonant frequency was designed for both cases. On the other hand, when the panel is filled with guadua fiber there is an increase in acoustic absorption amplitude and bandwidth.

\section{Conclusions}

The present work describes the complete process to build a perforated panel from bamboo fiber. In the first instance, it was necessary to obtain guadua fiber employing a mechanical-chemical method using sodium hydroxide. Subsequently, characterization of certain physical parameters of the fiber, such as humidity and density, was carried out. This with the purpose of obtaining a material that has the desired acoustic-mechanical properties. 
Measurement of acoustic properties of the material was carried out under current international standards (measurement of the absorption coefficient - taking into account corrections that must be made with respect to the calibration of the system and the measurement system), in order to finally carry out the design of the perforated panel.

Likewise, panel behavior within a room was validated, based on reverberation time measurement of the room with and without the panel. These results report a significant decrease in the reverberation time, which means that the panel fillet out with guadua fiber is a product that meets the acoustic requirements that were raised, in accordance with the principles of Sustainable Development.

\section{References}

[1] United Nations Conference. Environment \& Development Rio de Janerio. 3 to 14 June 1992, Brazil.

[2] Brundtland, G. H. The Brundtland Report. World Commission on Environment and Development. 1987.

[3] Beranek Leo. Acoustics. American Institute of Physics, 1986.

[4] Ortega, Basilio Pueo, and Miguel Romá Romero. Electroacústica: altavoces y micrófonos. Pearson Educación, 2003.

[5] Kleiner, Mendel. Electroacoustics. CRC Press, 2013.

[6] Rossi, Mario. Acoustics and electroacoustics. Artech House Publishers, 1988.

[7] Cox, Trevor, and Peter d'Antonio. Acoustic absorbers and diffusers: theory, design and application. Crc Press, 2016.ossi, Mario. Acoustics and electroacoustics. Artech House Publishers, 1988.

[8] Randall, F. Barron. "Industrial noise control and acoustics." Louisiana Tech Universitz Ruston, Louisiana, USA (2001).

[9] Alavedra, Pere, et al. "La construcción sostenible: el estado de la cuestión." Informes de la Construcción 49.451 (1997): 41-47.

[10] Bedoya Montoya, Carlos Mauricio. Construcción sostenible: para volver al camino. Biblioteca Jurídica Dike: Mares Consultoría Sostenible, 2011.

[11] Isbert, Antoni Carrión. Diseño acústico de espacios arquitectónicos. Vol. 4. Univ. Politèc. de Catalunya, 1998.

[12] Asdrubali, F. 2006. Survey on the acoustical properties of new sustainable materials for noise control. In: Euronoise 2006, May 30 - June 1, 2006, Tampere, Finland.

[13] D. A. Páez, M. Herrera Martínez and L. A. Calderón Bermúdez. Possibilities for the Development of Acoustic-Mechanical Systems based on Colombian Typical Fibres. In. Proceedings of ICSV23, Athens, Greece. 10-14 July, 2016.

[14] Colombian Technical Standard. "NTC 5525, Determination of the physical and mechanical properties of Guadua Angustifolia Kunth, Colombian Institute of Technical Standards (ICONTEC)." Liese, W (2007): 77-89.

[15] ISO Committee. Acoustics-Determination of sound absorption coefficient and impedance in impedance tubes-Part 2: Transfer function method. ISO CD, 1998, p. 10534-2. 